\title{
Morpheme-specific Phonology in Reduplication
}

\author{
Hannah Sande \\ UC Berkeley
}

\section{Introduction}

Reduplication is used in many languages to realize one or more morphosyntactic features. Often there are multiple different grammatical uses of reduplication within a single language. In such languages, the distinct reduplication processes may be subject to different phonotactic restrictions. In other words, reduplication can be associated with morpheme-specific or construction-specific phonology. Additionally, when the reduplicant is larger than a single segment, it can in some cases copy (supra)segmental material from more than one morpheme. This paper explores the locality domain of reduplication, that is, the amount of structure copied from in reduplication, specifically focusing on instances of reduplication subject to morpheme-specific phonology.

This paper examines two case studies of morpheme-specific reduplication that copy from a syntactic domain larger than a root but smaller than a word, providing an analysis in Cophonologies by Phase (Sande \& Jenks, 2018; Sande, 2019; Sande et al., 2020) (CBP). CBP assumes that lexical items, or vocabulary items in Distributed Morphology, include a morpheme-specific constraint weight adjustment, which applies to and scopes over the spell-out domain in which the morpheme is introduced. Spell-out domains are determined by syntactic phase boundaries (Chomsky, 2001, 2008). While other frameworks such as traditional Cophonology Theory (Orgun, 1996; Inkelas et al., 1997; Anttila, 2002; Inkelas \& Zoll, 2005, 2007) or indexed constraints (Pater 2007, 2010) can also account for the morpheme-specific phonological behavior of reduplicants, Cophonologies by Phase has the added benefit of straightforwardly accounting for the reduplication domain, or the amount of structure that serves as the base of reduplication in each case. This paper contributes to the growing literature on morphophonological interactions that can be accounted for within CBP.

The first case study discussed here comes from Guébie (Kru, Ivory Coast), where reduplication marks both nominalization and reciprocals (among others). In both morphosyntactic environments, reduplication copies the verb plus valency-changing affixes, but the reduplicants are subject to different sets of phonotactic restrictions. The second case study comes from Kinande (Bantu, Democratic Republic of Congo) where there is reduplication of nouns as well as verbs. Nominal and verbal reduplication both involve a two-syllable reduplicant that copies from the root plus some-but not all-affixes, and both are subject to a morpheme integrity constraint. However, the two reduplication processes in Kinande differ in whether they are prefixing or suffixing, whether they copy from right-to-left or left-to-right, and in which repair to the morpheme integrity constraint is preferred.

\section{Guébie morpheme-specific phonology in reduplication}

2.1 Guébie reduplication data In Guébie (Kru, Côte d'Ivoire) (Sande, 2017), there are a number of reduplication processes that serve as the primary exponent of morphosyntactic features, as well as regular reduplication in ideophones. This section focuses on two grammatical uses of reduplication in Guébie: reciprocal and nominalizing. As background, there are no underlying consonant clusters or codas in Guébie, and morphology tends to be non-concatenative (Sande, 2017). However, there is a series of valency-changing affixal morphology on verbs, including causative, passive, applicative, and iterative suffixes, as well as the reciprocal reduplication discussed here. There are also three nominalizing suffixes on verbs: an agentive

\footnotetext{
* Endless thanks to the Guébie community. Thank you to Xiang Li for her help in collating data for the typological survey of languages with multiple instances of reduplication. Thanks to Larry Hyman for discussion of the Kinande case study. Thanks also to the audience of AMP 2020 and the Morphology-Phonology Interface seminar at Georgetown University in Fall 2020 for their feedback. Any mistakes are the author's.
}

(C) 2021 Hannah Sande

Proceedings of AMP 2020 
suffix, an event nominalizing suffix, and the event nominalizing reduplication discussed here. There are also definite and plural suffixes on nouns.

2.1.1 Nominalizing reduplication data One way of nominalizing a verb is through reduplication, plus a suffix $/-\varepsilon /$. The reduplicant in these contexts is entirely faithful to the base, segmentally and tonally: kpra-kpra- $\varepsilon^{23.23 .2 ~ ' m a n i p u l a t i n g / m a n i p u l a t i o n ' . ~ V a l e n c y ~ c h a n g i n g ~ s u f f i x e s ~ o n ~ v e r b s ~ a r e ~ f u l l y ~ c o p i e d ~ i n ~}$ nominalizing reduplication (1). In all Guébie examples, tones are marked with superscript numerals 1-4, where 4 is high.

(1) man-ว-manว- $\varepsilon^{3.2 .3 .2 .2} \quad \mathrm{nu}^{4}$

drink-PASS-RED.NMLZ-NMLZ water

'drinking water' or 'water that is drunk' (cf. mana 3.3 'drink')

There does not seem to be a prosodic template limiting the size of nominalizing reduplicants; the entire verb stem (root + valency changing morphology) is reduplicated no matter how many syllables.

Nominal suffixes like the definite and plural can occur outside of the nominalizing morphology (2a). These are not doubled in nominalizing reduplication $(2 b, c)$.
a. $6 r u-6 r u-j \varepsilon-a^{3.3 .2 .2}$
fly-RED.NMLZ-NMLZ-DEF
'the flying'
b. *6ru-6ru-je-a-a 3.3 .2 .2 .2
c. *6ru-a-6ru-a-je $\varepsilon^{3.3 .3 .3 .2}$

2.1.2 Reciprocal reduplication data Reciprocals are also marked by reduplication of verb stems, with the addition of a suffix $/-\mathrm{li}^{2} \%$. In reciprocal reduplication, the reduplicant always has a level tone 2 melody (kpra-kpra-lir ${ }^{23.2 .2 ~ ' m a n i p u l a t e ~ e a c h ~ o t h e r ') . ~ L i k e ~ n o m i n a l i z i n g ~ r e d u p l i c a t i o n, ~ o t h e r ~ v a l e n c y-c h a n g i n g ~ a f f i x e s ~}$ are copied in reciprocal reduplication (3).
(3) $\mathrm{a}^{3}$
bido-li-bidoli-li'.3.2.2.2.2.2.2
$\operatorname{safri}^{4.1}$
2PL.NOM wash.PFV-APPL-RED.RECIP-RECIP soap
'You all washed each other with soap.'

In reciprocal (4), but not nominalizing contexts (5), there is a phonotactic ban on consecutive implosive consonants. The reduplicant is underlined in (4-6).

(4) Reciprocal 'know'

a. wa $^{3} \quad$ ji-6e-le-li 3 .1.2.2

3PL.NOM PART-knOW-RED.RECIP-RECIP

'They know each other'

b. *ji-6e- $\underline{6 e-1 i}{ }^{3 \cdot 1.2 .2}$

(5) Nominalized 'know'

a. ji-6e-6e- $\varepsilon^{3.1 .1 .2}$ PART-knOW-RED.NMLZ-NMLZ 'knowing'

b. *ji-6e-le- $\varepsilon^{3 \cdot 1 \cdot 1.2}$

This ban only applies to consecutive implosives (6).

(6) $\mathrm{wa}^{3} \quad$ bate-6ate-lit.2.2.2.2

3PL.NOM search.PFV-RED-RECIP

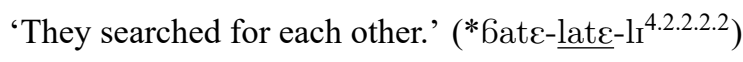


2.1.3 Phonological differences across reduplication types While both reciprocal and nominalizing reduplication seem to copy the entire verb stem, they differ in their phonotactic requirements. In nominalizing reduplication, the reduplicant is faithful to the input segments and tones, while in reciprocal reduplication the tone of the reduplicant is a level tone 2 regardless of the tone of the base, and consecutive implosive consonants are prohibited (7).

(7) Guébie reduplication

\begin{tabular}{|c|c|c|c|}
\hline Verb & Meaning & Reciprocal & Nominalized \\
\hline a. $\quad \mathrm{li}^{3}$ & 'eat' & li-li-li 3.2 .2 & li-li- $\varepsilon^{3.3 .2}$ \\
\hline b. bido $^{2.3}$ & 'bathe' & bido-bido-li ${ }^{2 \cdot 3 \cdot 2 \cdot 2 \cdot 2}$ & bido-bido- $\varepsilon^{2.3 .2 .3 .2}$ \\
\hline $\mathrm{ji}-6 \mathrm{e}^{3.1}$ & 'know' & ji-6e-le-li ${ }^{3.1 .2 .2}, * j \mathrm{ji}-6 \mathrm{e}-6 \mathrm{e}-\mathrm{li}^{3.1 .2 .2}$ & $\mathrm{ji}-6 \mathrm{e}-\underline{6 \mathrm{e}-\varepsilon^{3}} .1 .1 .2$ \\
\hline
\end{tabular}

2.1.4 Double reduplication For some speakers, it is possible for both reduplication processes to occur on the same verb stem (8), though even speakers who allow this construction prefer to use an alternative nominalization strategy in such cases (9). In (9), the event nominalizing suffix $/-\mathrm{li}^{2} /$ is used instead of reduplication plus /-E/. In both (8) and (9) the reciprocal is underlines and the nominalizer is bold.

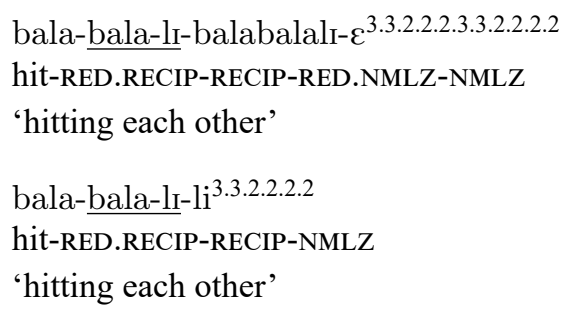

The double reduplication in (8) differs from previously described cases of double reduplication, as in Salishan languages, for example (Urbanczyk, 2001; Stonham, 2004). In Salish, each reduplicant only copies one syllable (or less), so two instances of reduplication on the same stem result in three consecutive syllables containing two reduplicants and a base syllable: bí-bəd-bəda?, DIM-DIST-Root, 'dolls, litter' (Urbanczyk, 2001:p. 169).

In Guébie, the reciprocal reduplication occurs inside of the nominalization reduplication. Reciprocal reduplication copies the entire verb stem to that point and adds $/-\mathrm{li}^{2} /$. Then nominalizing reduplication copies the entire verb stem, including the reciprocal reduplication, and adds $/-\varepsilon /$, resulting in four copies of the verb root (8).

2.1.5 Interim summary Two different reduplication processes within a single language can be subject to different phonotactic restrictions or constraints. Some of these may be analyzable as differences in underlying phonological form of the reduplicative morpheme, such as the difference in tone melody on the reduplicant in reciprocal versus nominalization contexts in Guébie. Others, like the ban on consecutive implosives in the reciprocal construction, seem to require morpheme-specific phonology. Additionally, the morphemes copied in reduplication in both constructions seem to include everything that is hierarchically lower than the morpheme triggering reduplication. The analysis in the following section attempts to account for the morpheme-specific phonotactic restrictions and locality domain of reduplication in Guébie.

2.2 An analysis of Guébie reduplication in Cophonologies by Phase Sande (2019) proposes that Voice is a syntactic phase head in Guébie, as it is the domain of a number of morphophonological processes including root-controlled ATR and nasal harmony and enclitic-controlled full vowel harmony. This same domain-the bold morphemes in the verbal template in (10)-is reduplicated in reciprocal contexts in Guébie.

$$
\begin{aligned}
& \text { Verbal morphology template } \\
& \text { PART }- \text { Root }-\left[\begin{array}{c}
\text { CaUs } \\
\text { Pass }
\end{array}\right]-\text { APPL }- \text { ReCIP }-\left[\begin{array}{c}
\text { NMlz1 } \\
\text { Nmlz2 } \\
\text { Agt } \\
\text { ObJ }- \text { POLARQ }
\end{array}\right]
\end{aligned}
$$


Nominalizing suffixes attach outside the Voice domain and so are not subject to reduplication. ${ }^{1}$ Nominalizers introduce a second phase, headed by $n$. Object enclitics and polar question particles are enclitics on the auxiliary or verb in the immediately post-subject position, and are also outside the Voice domain. Root and valency changing morphology within the Voice domain, but not additional structure, is reduplicated in reciprocal contexts.

CBP vocabulary items contain three components: phonological input features, segments, and suprasegmentals $(\mathcal{F})$; a prosodic subcategorization frame $(\mathcal{P})$; and a morpheme-specific constraint ranking $(\mathcal{R})$. The proposed vocabulary item for the reciprocal morpheme is provided in (11).

$$
[\mathrm{RECIP}] \longleftrightarrow\left\{\begin{array}{cc}
\mathcal{F}: & \mathrm{RED}^{2}, l i^{2} \\
\mathcal{P}_{1}: & -\mathrm{RED}-l i]_{\omega} \\
\mathcal{R}_{1}: & \text { OCP-6 } \gg \text { IDENT-BR }
\end{array}\right\}
$$

The reduplicant morpheme is listed in the input as RED, with a tone 2 melody $(\mathcal{F}$ in 11$)$. The $\mathcal{P}$ specifies that the reduplicant and /-li/ are suffixes that surface within a prosodic word. The $\mathcal{R}$ specifies a partial constraint ranking that must hold in the phonological grammar during evaluation of the spell-out domain in which this morpheme is introduced and evaluated.

Here I adopt Base-Reduplicant Correspondence Theory (BRCT) (McCarthy \& Prince, 1995) to ensure faithfulness between the reduplicant and base. The choice to use BRCT is not crucial to the analysis, and other constraint-based reduplication mechanisms could also be used effectively. In the default grammar of the language, the relevant constraint ranking is ID-TONE, IDENT-BR $\gg$ OCP-6. When a phase containing the reciprocal morpheme in (11) is spelled out, the relevant phonological constraint ranking is as in (12). Faithfulness between the base and reduplicant is only non-optimal when the result would be a violation of OCP-6, which prohibits consecutive /6/ segments (12b), or a violation of IDENT-TONE (12c,d), (13b).

\begin{tabular}{|c|c|c|c|}
\hline$\left[\omega 6 \mathrm{e}^{1}-\mathrm{RED}^{2}-\mathrm{li}^{2}\right.$ & ID-TONE & $\mathrm{OCP}$ & ID-BR \\
\hline 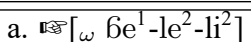 & & & *** \\
\hline b. $\left[\omega 6 e^{1}-6 e^{2}-1 i^{2}\right]$ & & $* !$ & * \\
\hline c. $\left[\omega 6 \mathrm{e}^{1}-\mathrm{le}^{1}-\mathrm{li}^{2}\right]$ & $* !$ & 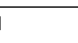 & * \\
\hline d. $\left[\omega 6 \mathrm{e}^{1}-6 \mathrm{e}^{1}-1 \mathrm{i}^{2}\right]$ & *! & $*$ & \\
\hline
\end{tabular}

\begin{tabular}{|l||c|c|c|}
\hline$\left[\omega\right.$ bido $^{2.3}-$-ED $^{2}-\mathrm{li}^{2}$ & ID-TONE & OCP & ID-BR \\
\hline \hline a. ${ }^{\infty}\left[\omega\right.$ bido $^{2.3}-$ bido $\left.^{2.2}-\mathrm{li}^{2}\right]$ & & & $*$ \\
\hline b. $\left[\omega \operatorname{bido}^{2.3}-\right.$ bido $\left.^{2.3}-\mathrm{li}^{2}\right]$ & $* !$ & & \\
\hline
\end{tabular}

The reciprocal morpheme triggering reduplication is introduced within the Voice phase. Spell-out at phase boundaries ensures that no morpheme introduced hierarchically higher than Voice, such as nominalizers, will be reduplicated, since those morphemes are not present in the derivation when reduplication takes place: * $[\omega$ bidobidolilili 2.3.2.2.2.2.2 $]$.

After the Voice phase is phonologized, the syntactic structure continues to be built, and at the next phase boundary, perhaps $n$, the structure is phonologized again. Non-reduplicating nominalizers /-nכ/ and /-li/ are not associated with morpheme-specific constraint rankings, so are subject to the default grammar of the language, where IDENT-BR $\gg$ OCP- 6 . These nominalizers are introduced outside the phase domain where reduplication is triggered (Voice), so they are not reduplicated. Adding a /-li/ nominalizer to the output of (13) would result in $\left[\omega\right.$ bidobidoli $\left.{ }^{2.3 .2 .2 .2}-\mathrm{li}^{2}\right]$ 'washing each other'. Here the input to the phonology includes the output of the previous phase, the optimal candidate in (13), plus the nominalizer $/-1 i^{2} /$. The default grammar applies and the optimal candidate is the one faithful to the input.

The reduplicating nominalizer, like other nominalizers, is not associated with a morpheme-specific constraint ranking, $\mathcal{R}$ (14), but it introduces a RED morpheme, triggering reduplication. The default ranking of ID-BR $\gg$ OCP will result in faithful reduplication and no OCP effects, as desired.

\footnotetext{
1 The prefixing particle in particle verb constructions is not reduplicated, though it is part of the domain of ATR and nasal harmony. The reduplication facts can be explained if the particle is added to the verbal word in a later morphosyntactic cycle, though the specifics of the behavior of the particle are left for future work.
} 
(14) $[$ NMLZ $] \longleftrightarrow\left\{\begin{array}{cc}\mathcal{F}: & \text { RED, } \varepsilon \\ \mathcal{P}_{1}: & -\mathrm{RED}-\varepsilon]_{\omega} \\ \mathcal{R}_{1}: & \emptyset\end{array}\right\}$

The input to the phonology at the $n$ phase level is the previously spelled out Voice phase plus the nominalizing morpheme in (14). Consider a nominalized verb that is not also reciprocal, such as $[\omega$ bidobido- $\mathrm{e}^{2.3 .2 .3 .2}$ ] 'washing'. The $n$ is not associated with a tone melody, so the tone of the reduplicant is copied faithfully from the base. The default ranking of IDENT-BR $\gg$ OCP-6 results in identical reduplicant and base (15), even when the result is consecutive implosive consonants (16).

\begin{tabular}{|l||c|c|c|}
\hline$\left[\omega\right.$ bido $^{2.3}-$ RED- $\left.^{2}\right]$ & ID-TONE & ID-BR & OCP \\
\hline \hline a. ${ }^{2}\left[\omega\right.$ bido $^{2.3}-$ bido $\left.^{2.3}-\varepsilon^{2}\right]$ & & & \\
\hline b. $\left[\omega\right.$ bido $^{2.3}-$ bido $\left.^{2.2}-\varepsilon^{2}\right]$ & $* !$ & & \\
\hline
\end{tabular}

\begin{tabular}{|l||c:c|c|}
\hline$\left[\omega 6 \mathrm{e}^{1}-\mathrm{RED}-\varepsilon^{2}\right]$ & ID-TONE & ID-BR & OCP \\
\hline \hline a. ${ }^{-}\left[\omega 6 \mathrm{e}^{1}-6 \mathrm{e}^{1}-\varepsilon^{2}\right]$ & & & $*$ \\
\hline b. $\left[\omega 6 \mathrm{e}^{1}-\mathrm{le}^{1}-\varepsilon^{2}\right]$ & & $* !$ & \\
\hline
\end{tabular}

When a reciprocal and reduplicating nominalizer are present in the same clause, both reduplication processes apply separately, reciprocal reduplication at the Voice phase as in (12) and nominalizing reduplication at the $n$ phase, as in (17). The input to (17) is the output of tableau (12) plus the reduplicating nominalizing morpheme in (14).

\begin{tabular}{|c|c|c|c|}
\hline$\left[\omega\right.$ Geleli ${ }^{1.2 .2}-{ }^{1}$ RED- $\left.\varepsilon^{2}\right]$ & ID-TONE & ID-BR & $\mathrm{OCP}$ \\
\hline 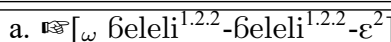 & & & \\
\hline b. $\left[\omega\right.$ 6eleli ${ }^{1.2 .2}-6$ eleli $\left.^{2 \cdot 2.2}-\varepsilon^{2}\right]$ & $* !$ & * & \\
\hline
\end{tabular}

Phase-based spell-out predicts that reduplication should apply to the syntactic phase domain within which the triggering morpheme is introduced, and no hierarchically higher morphemes (outside the phase) should be affected. Morpheme-specific constraint rankings in vocabulary items ensure that different reduplicationtriggering morphemes can be associated with different phonotactic requirements.

Other previous multiple-spell-out approaches that assume multiple phonological grammars within a single language could also account for these facts. These include frameworks such as traditional Cophonology Theory (Anttila, 2002; Inkelas \& Zoll, 2005, 2007) and Stratal OT (Bermúdez-Otero, 1999; Kiparsky, 2000, 2008). The generalization lost in such alternative models is that the amount of structure in the reduplicant aligns with relevant syntactic boundaries, namely phase boundaries, such as the VoiceP in Guébie, widely accepted to be a syntactic phase domain across languages (Chomsky, 2001, 2008). In the following section we will see yet another example of reduplication aligning with a syntactic phase boundary.

\section{Kinande morpheme-specific reduplication}

3.1 Kinande reduplication data In Kinande (Bantu, Democratic Republic of the Congo), there are reduplication processes in the nominal domain and verbal domain (Mutaka \& Hyman, 1990; Downing, 1997, 1998, 2000; Hyman et al., 2009). The two reduplication processes differ in whether they are prefixing or suffixing, and in their repairs to a morpheme integrity constraint. For a more complete description of the Kinande facts than what is presented here, see Mutaka \& Hyman (1990).

3.1.1 Nominal reduplication Nominal reduplication, meaning "a real (noun)", is two syllables, suffixal, and copies from the right to left of the base, which includes the root and class prefixes (18a-b), but not the augment (18d). When there are fewer than two syllables in the base, the reduplicant doubles the base again (18d) (Mutaka \& Hyman, 1990). Tone of the base is copied faithfully in the reduplicant, but with a predictable low tone on the final vowel, which is general in the language and not specific to nominal reduplication. 
(18) Kinande nominal reduplication
a. ku-gulu
ku-gulu-gulu
'a real leg'
b. o-mú-kàlì
o-mú-kàlì-kàlì
'a real woman'
c. o-mú-twe
o-mú-twé-mútwe 'a real head'
d. e-n-da
e-n-da.nda.nda
'a real belly'
e. o-mú-herukì
*e-n-da-e.nda
'bride'

The nominal reduplicant is always two syllables, no matter how many syllables are in the verb root or stem. We know that nominal reduplication is suffixing rather than prefixing because the /mu-/ class prefix is within the domain of reduplication (18c), but it is not copied in the reduplicant when the root is two syllables and fills the two-syllable template (18b). If nominal reduplication were prefixing, we would expect the ungrammatical form *omúkàkàlı̀ rather than o-mú-kàlì-kàlı̀ in (18b).

When the root or right-most morpheme in the base is longer than two syllables, reduplication is impossible (18e). That is, a partial morpheme cannot be reduplicated. Mutaka \& Hyman (1990) analyze this as due to a morpheme integrity constraint, an approach that is adopted here as well.

3.1.2 Verbal reduplication In verbal reciprocal reduplication, the reduplicant is also two syllables, but is prefixal (19). It copies from the verb root and suffixes. Like nominal reduplication, it is subject to a morpheme integrity constraint; however, unlike for nominal reduplication, there is a viable repair to the morpheme integrity constraint; namely, a dummy segment $a$ is inserted rather than copying a partial morpheme (19b-c) (Mutaka \& Hyman, 1990).

(19) Kinande verbal reduplication
a. e-ri-sw-er-a e-ri-swera-sw-er-a 'to grind for e.o.'
b. e-ri-hum-ir-a e-ri-hum-a-hum-ir-a 'to beat for e.o.'
c. tu-tum-ír-ê tu-tum-a-tum-ír-ê, 'let's send to e.o.'
*tu-tum-e/i-tum-ir-e

The reduplicant is always two syllables. We know that it is prefixing rather than suffixing because if it were suffixing we would expect the /-ir/ suffix and not the root to be copied in $(19 \mathrm{~b}, \mathrm{c})$, but it is not: *tu-tumir-e-ire.

The reduplicant cannot be larger than two syllables, as it would be if both the root and /-ir/ suffix were copied in (19c), since codas are disallowed in Kinande: *tu-tumir-tum-ir-e. In (19c) we see that copying part of the applicative /-ir/ morpheme is impossible, *tu-tumi-tum-ir-e. Rather, when reduplication would result in copying a partial morpheme, to fill the two-syllable template of the reduplicant, a default segment $a$ is added: tu-tum-a-tum-ir-ê.

3.1.3 Phonological differences across reduplication types Nominal and verbal reduplication in Kinande both copy two syllables from the base. However, nominal reduplication is suffixing while verbal reduplication is prefixing. Accordingly, nominal reduplication copies from the right edge of the base, and verbal reduplication copies from the left edge. Additionally, a morpheme integrity constraint, prohibiting copying of a partial morpheme, is active in both nominal and verbal reduplication, but with different repairs in each case: (18d) vs. (19c).

The next section presents an analysis of the prefixing versus suffixing differences, the morpheme-specific repairs to the morpheme integrity constraint, and the amount of structure copied in reduplication.

3.2 An analysis of Kinande reduplication in Cophonologies by Phase The vocabulary item for nominal reduplication, meaning "a real $\mathrm{X}$ " is introduced in (20). I call the morphosyntactic feature that introduces this meaning simply $\mathrm{F}$, for the purposes of this paper.

$$
[\mathrm{F}] \longleftrightarrow\left\{\begin{array}{cc}
\mathcal{F}: & \text { RED } \\
\mathcal{P}_{1}: & -\mathrm{RED}]_{\omega} \\
\mathcal{R}_{1}: & \text { DEP } \gg \text { REALIZEMORPH }
\end{array}\right\}
$$


This $[\mathrm{F}]$ feature must be a nominalizer itself, or attach inside the domain of nominalization, in order to be spelled out within the $n$ phase, containing roots and class markers ( $n$ heads themselves, similar to, say Kramer \& Kramer (2015)'s analysis of gender). I remain agnostic as to the head that introduces [F].

The prosodic subcategorization $\mathcal{P}$ specifies that the reduplicant is a suffix.

Following Mutaka \& Hyman (1990) I assume a highly ranked MoRPHEMEINTEGRITY constraint in the language, prohibiting a partial morpheme from surfacing. Base-Reduplicant Correspondence is again adopted to account for reduplication. The morpheme-specific $\mathcal{R}$ associated with the reciprocal morpheme in (20) ensures that epenthesis is penalized more than not realizing a morpheme. The results is that insertion is not a viable solution to MORPHEMEINTEGRITY violations, and reduplication is impossible. ${ }^{2}$

A tableau showing the derivation of nominal reduplication in the presence of the above vocabulary item is given in $(21,22)$. The highly ranked ID-BR and RED=FoOT result in a 2-syllable reduplicant that matches the features of its base (21). However, when the base is longer than two syllables (one foot), not reduplicating is preferable to insertion of dummy segments (22). Since the tonal alternations in nominal reduplication contexts are predictable given the regular phonology of the language, I do not include tonal constraints here.

\begin{tabular}{|c|c|c|c|c|c|}
\hline [ ${ }_{\omega}$ mú-twe-RED] & MORPHINTEG & ID-BR & RED $=$ FOOT & DEP & REALIZEMORPH \\
\hline a. $[\omega$ mú-twé-mútwe $]$ & & & & & \\
\hline b. [w mú-twé-útwe] & $* !$ & & & & \\
\hline c. [w mú-twé-mútwa] & & $* !$ & & & \\
\hline d. [ ${ }_{\omega}$ mú-twé-twe] & & & $* !$ & & \\
\hline e. [w mú-twé-átwe] & & & & *! & \\
\hline
\end{tabular}

\begin{tabular}{|l||c:c:c|c|c|}
\hline$[\omega$ mú-herukì-RED $]$ & MoRPHINTEG & ID-BR & RED=FoOT & DEP & REALIzEMORPH \\
\hline \hline a. $[\omega$ mú-herukì-ruki $]$ & $* !$ & & & & \\
\hline b. $[\omega$ mú-herukì-heruki $]$ & & & $* !$ & & \\
\hline c. $[\omega$ mú-herukì-jaja $]$ & & & & $* !$ & \\
\hline d. ${ }^{\circ}[\omega$ mú-heruki $]$ & & & & & $*$ \\
\hline
\end{tabular}

The RED morpheme and BRCT constraints result in reduplication, while the morpheme-specific constraint ranking of DEP over REALIZE results in no reduplication at all $^{3}$ as a morpheme-specific repair to violations of MORPHEMEINTEGRITY.

Morphemes introduced outside of the $n$ phase (class marker, $\mathrm{F}+$ root) are outside the domain of reduplication because they are introduced to the derivation after reduplication applies; that is, they are added after the phase containing the $\mathrm{F}$ feature. The augment prefix is outside the domain of nominal reduplication.

In verbal contexts, a reciprocal morpheme triggers reduplication (23).

$$
[\text { Recip }] \longleftrightarrow\left\{\begin{array}{cc}
\mathcal{F}: & \text { RED } \\
\mathcal{P}_{1}: & {[\omega \text { RED }-} \\
\mathcal{R}_{1}: & \emptyset
\end{array}\right\}
$$

The $\mathcal{P}$ specification of the reciprocal morpheme differs from that of the $\mathrm{F}$ morpheme in that it is specified as a prefix rather than a suffix. Upon evaluating the phase containing the reciprocal morpheme, the reduplicant is left-most in the prosodic word. In later cycles of syntax and phonology, additional structure may be added to the left edge, such as augments and subject- and object-marking prefixes.

A crucial difference between the phonological grammar in nominal reduplication versus verbal reduplication contexts is that verbal reduplication is subject to the default constraint ranking of the language, which includes RealizeMorPh $\gg$ DeP. There is no $\mathcal{R}$ associated with the reciprocal morpheme. The result is reduplication when the reciprocal RED morpheme is present, but when the MorPHEMEINTEGRITY constraint would otherwise be violated, it is repaired via insertion due to the default ranking of ReALIzE

\footnotetext{
2 The two-syllable template associated with the reduplicant could be analyzed as due to the shape of the input, or as due to a constraint like RED=FOOT. I non-crucially adopt the constraint RED=FoOT, though this choice has no bearing on the arguments of the paper.

3 It is unclear from the description in Mutaka \& Hyman (1990) whether the repair is simply not to reduplicate (22d), or whether there is no way to express 'a real bride' in Kinande, leading to ineffability. Hyman (p.c.) says it is likely ineffability, in which case minimal modification to the tableau in (22) is required.
} 
$\gg$ DEP. A tableau showing verbal reduplication is given in (24), and insertion of dummy segments when MORPHEMEINTEGRITY would otherwise be violated is shown in (25).

\begin{tabular}{|c|c|c|c|c|}
\hline$[\omega$ RED-sw-er-a $]$ & MORPHINTEG ID-BR & RED $=$ FOOT & REALIZEMORPH & DEP \\
\hline a. $[\omega$ swera-sw-er-a $]$ & 1 & & & \\
\hline b. $[\omega$ swer-sw-er-a] & $* !$ & & & \\
\hline c. $[\omega$ sw-er-a $]$ & I & & $* !$ & \\
\hline d. $[\omega$ jaja-swera $]$ & 1 & & & $* !$ \\
\hline
\end{tabular}

\begin{tabular}{|c|c|c|c|c|c|}
\hline [ $\omega$ RED-tum-ír-e] & MORPHINTEG & ID-BR & RED $=$ FOOT & REALIZEMORPH & DEP \\
\hline a. $[\omega$ tuma-tum-ír-e $]$ & & & & & * \\
\hline b. [ $\omega$ tumi-tum-ír-e] & $* !$ & & & & \\
\hline c. $[\omega$ tum-tum-ír-e $]$ & & & $* !$ & & \\
\hline d. $[\omega$ tum-ír-e $]$ & & & & $* !$ & \\
\hline
\end{tabular}

Morphemes introduced outside the macro-stem, or the Voice phase boundary (Julien, 2002; Cheng \& Downing, 2016), are not subject to reduplication: *eri-eriswera 'to grind for e.o' (cf. 19a). This is predicted by a phase-based spell-out approach like CBP. Additionally, the different repairs to the morpheme integrity constraint in nominal versus verbal reduplication contexts are predicted in an approach where vocabulary items are associated with morpheme-specific constraint rankings.

\section{Discussion}

In addition to the Guébie and Kinande cases discussed above, there are hundreds of languages with more than one reduplication process. ${ }^{4}$ In Salishan languages, for example, there are reduplication processes to mark augmentative, diminutive, and continuative, along with other grammatical meanings (Urbanczyk, 2001; Stonham, 2004; Czaykowska-Higgins \& Kinkade, 2011). Each grammatical reduplication process has a different reduplication target (the stressed syllable versus the initial syllable or consonant of the stem), and the reduplicants are of different shapes (CV versus $\mathrm{CVC}$ ).

This paper has focused on two specific aspects of reduplication-morpheme-specific phonotactic restrictions and the amount of structure copied-providing an analysis in Cophonologies by Phase. As discussed in section 2.2, alternative models such as Cophonology Theory and Stratal OT could account for the morphemespecific phonotactic restrictions across reduplication contexts, but would lose the generalization that locality domains of reduplication align with syntactic phase boundaries.

4.1 Morpheme-specific phonology Some of the differences in reduplicant phonotactics within a single language maybe accounted for with differences in underlying form of the relevant morpheme. For example, different reduplication processes in Salishan languages surface with different CV templates, which could be analyzed as a difference in input shape: CV versus CVC (Urbanczyk, 2001; Stonham, 2004; CzaykowskaHiggins \& Kinkade, 2011). In Guébie, the tonal difference between the nominalization and reciprocal reduplication morphemes could be that one is underlyingly specified as tone- 2 while the other is not underlyingly specified for tone (as in the analysis presented in section 2.2). However, there are also differences that cannot straightforwardly be accounted for in the underlying form of the reduplicating morpheme. These include the OCP constraint on implosives in Guébie reciprocal reduplication contexts, not active elsewhere in the language, and the different repairs to the morpheme integrity constraint at play in Kinande nominal and verbal reduplication. These seem to be morpheme-specific phonological requirements that cannot be accounted for by differences in underlying form. I take these differences across reduplication processes within a language as evidence for morpheme-specific phonology, and have provided an analysis in Cophonologies by Phase (Sande \& Jenks, 2018; Sande, 2019; Sande et al., 2020).

The morpheme-specific phonotactic requirements across reduplication contexts presented here bear on the item versus process debate in morpho-phonology (Hockett, 1954; Anderson, 1992; Zimmermann, 2013; Sande, 2018), showing that while some morpheme-specific phonological properties may be attributed to differences in underlying form, some must be processes sensitive to morphophonological context.

\footnotetext{
4 In forthcoming work I present a typological survey of over 250 languages with reduplication, specifically focusing on those that use reduplication for more than one morphosyntactic purpose, and where there are different phonological requirements in different reduplication contexts.
} 
4.2 Locality domain of reduplication Additionally, this work provides a novel account of the amount of structure subject to copying in reduplication based on syntactic structure. The typological data show that the amount of structure in the base of a reduplicant tends to be co-extensive with a syntactic phase domain, supporting the cyclic application of morphology and phonology at phase boundaries (Kratzer \& Selkirk, 2007; Pak, 2008; Jenks \& Rose, 2015; Sande, 2017; Kastner, 2019).

Previous work in Cophonologies by Phase has shown that numerous other phonological properties are subject to locality restrictions that align with syntactic phase boundaries. Specifically, phase-based phonological evaluation has been shown to account for category-specific phonology (Sande et al., 2020), doubly morphologically conditioned phonology (Sande, 2020), phonological processes that apply to a domain smaller than a word (Sande, 2019), and phonological processes that apply to a domain larger than a word (Sande et al., 2020). This paper builds on this previous work, showing that reduplication, too, is subject to locality restrictions determined by syntactic phase boundaries. The CBP analysis presented here predicts that morphemes introduced in syntactic phases higher than the one in which the reduplication-triggering morpheme is introduced will not be reduplicated.

Future work will investigate potential challenges for this approach. For example, many Bantu languages show reduplication of verb stems. However, the specific morphemes that can be copied in reduplication vary across Bantu languages. In some languages, object-marking prefixes can be copied along with the root and valency-changing suffixes (as in Ndebele (Hyman et al., 2009)), while in others they are outside the domain of reduplication (as in Kinande, discussed in section 3). Whether these differences are due to differences in syntactic structure, morphology, or phonological requirements is under investigation. The answer will determine whether languages like Ndebele pose a challenge for a phase-based view of reduplication domains.

\section{References}

Anderson, Stephen R. (1992). A-morphous morphology. Cambridge University Press, Cambridge.

Anttila, Arto (2002). Morphologically conditioned phonological alternations. Natural Language \& Linguistic Theory 20:1, $1-42$.

Bermúdez-Otero, Ricardo (1999). Constraint interaction in language change: quantity in English and Germanic. Doctoral dissertation, University of Manchester.

Cheng, Lisa Lai-Shen \& Laura J Downing (2016). Phasal syntax= cyclic phonology? Syntax 19:2, 156-191.

Chomsky, Noam (2001). Derivation by phase. Kenstowicz, Michael (ed.), Ken Hale: A life in language, Cambridge, MA: MIT Press, 1-52.

Chomsky, Noam (2008). On phases. Freiden, Robert, Carlos P. Otero \& Maria Luisa Zubizarreta (eds.), Foundational issues in linguistic theory: essays in honor of Jean-Roger Vergnaud, MIT Press, Cambridge, 133-166.

Czaykowska-Higgins, Ewa \& M Dale Kinkade (2011). Salish languages and linguistics: Theoretical and descriptive perspectives, vol. 107. Walter de Gruyter.

Downing, Laura J (1997). Morphological correspondence in Kinande reduplication. Annual Meeting of the Berkeley Linguistics Society, vol. 23, 83-94.

Downing, Laura J (1998). Prosodic misalignment and reduplication. Yearbook of morphology 1997, Springer, 83-120.

Downing, Laura J (2000). Morphological and prosodic constraints on Kinande verbal reduplication. Phonology 17:1, $1-38$.

Hockett, Charles F (1954). Two models of grammatical description. Word 10:2-3, 210-234.

Hyman, Larry M, Sharon Inkelas \& Galen Sibanda (2009). Morphosyntactic correspondence in bantu reduplication. The nature of the word: Essays in honor of Paul Kiparsky 273-310.

Inkelas, Sharon \& Cheryl Zoll (2005). Reduplication: Doubling in morphology, vol. 106. Cambridge University Press.

Inkelas, Sharon \& Cheryl Zoll (2007). Is grammar dependence real? A comparison between cophonological and indexed constraint approaches to morphologically conditioned phonology. Linguistics 45.1, 133-171.

Inkelas, Sharon, Orhan Orgun \& Cheryl Zoll (1997). The implications of lexical exceptions for the nature of grammar. McCarthy, J. J. (ed.), Optimality Theory in Phonology: A Reader, Blackwell, Oxford, 542-551.

Jenks, Peter \& Sharon Rose (2015). Mobile object markers in Moro: The role of tone. Language 91:2, $269-307$.

Julien, Marit (2002). Syntactic heads and word formation. Oxford University Press on Demand.

Kastner, Itamar (2019). Templatic morphology as an emergent property: Roots and functional heads in Hebrew. Natural Language and Linguistic Theory 1-49.

Kiparsky, Paul (2000). Opacity and cyclicity. The linguistic review 17, 351-367.

Kiparsky, Paul (2008). Fenno-Swedish quantity: Contrast in Stratal OT. Vaux, Bert \& Andrew Nevins (eds.), Rules, constraints, and phonological phenomena, Oxford University Press, Oxford.

Kramer, Ruth \& Ruth T Kramer (2015). The morphosyntax of gender, vol. 58. Oxford University Press.

Kratzer, Angelika \& Elisabeth Selkirk (2007). Phase theory and prosodic spellout: The case of verbs. The Linguistic Review 24, 93-135. 
McCarthy, John J \& Alan S Prince (1995). Faithfulness and reduplicative identity. GLSA (Graduate Linguistic Student Association), Dept. of Linguistics .

Mutaka, Ngessimo \& Larry M Hyman (1990). Syllables and morpheme integrity in Kinande reduplication. Phonology 73-119.

Orgun, Cemil (1996). Sign-based morphology and phonology with special attention to Optimality Theory. Unpublished dissertation, UC Berkeley.

Pak, Marjorie (2008). The postsyntactic derivation and its phonological reflexes. Ph.D. thesis, University of Pennsylvania.

Sande, Hannah (2017). Distributing morphologically conditioned phonology: Three case studies from Guébie. Ph.D. thesis, UC Berkeley.

Sande, Hannah (2018). Cross-word morphologically conditioned scalar tone shift in Guébie. Morphology 28, $253-295$.

Sande, Hannah (2019). A unified account of conditioned phonological alternations: Evidence from Guébie. Language 95(3), 456-497.

Sande, Hannah (2020). Morphologically conditioned phonology with two triggers. Phonology 37:3, 453-493.

Sande, Hannah \& Peter Jenks (2018). Cophonologies by phase. NELS 48 Proceedings .

Sande, Hannah, Peter Jenks \& Sharon Inkelas (2020). Cophonologies by ph(r)ase. Natural Language and Linguistic Theory 1-51.

Stonham, John (2004). Linguistic theory and complex words: Nuuchahnulth word formation. Springer.

Urbanczyk, Suzanne (2001). Patterns of reduplication in Lushootseed. Psychology Press.

Zimmermann, Eva (2013). Non-concatenative allomorphy is generalized prosodic affixation: The case of Upriver Halkomelem. Lingua 134, 1-26. 